\title{
Cardiac magnetic resonance imaging is more diagnostic than 2-dimensional echocardiography in determining the presence of bicuspid aortic valve
}

\author{
S. Chris Malaisrie, MD, ${ }^{\mathrm{a}}$ James Carr, MD, ${ }^{\mathrm{c}}$ Issam Mikati, MD, ${ }^{\mathrm{b}}$ Vera Rigolin, MD, ${ }^{\mathrm{b}}$ Byron K. Yip, BA, ${ }^{\mathrm{a}}$ \\ Brittany Lapin, MPH, ${ }^{\mathrm{a}}$ and Patrick M. McCarthy, $\mathrm{MD}^{\mathrm{a}}$
}

Objective: This study compares 2-dimensional, transthoracic echocardiography with cardiac magnetic resonance imaging in the preoperative identification of bicuspid aortic valve before aortic valve surgery.

\begin{abstract}
Methods: Of 1203 patients who underwent an aortic valve operation, 218 had both preoperative transthoracic echocardiography and cardiac magnetic resonance imaging. Patients in the study group were aged 56 years and had an ejection fraction of $56 \%, 76 \%$ were male, and $29 \%$ had associated coronary artery disease. The results of transthoracic echocardiography and cardiac magnetic resonance imaging were classified as bicuspid aortic valve, trileaflet aortic valve, or nondiagnostic. Of the 218 patients, $123(56 \%)$ had bicuspid aortic valve as determined at the time of surgery and $116(53 \%)$ had an ascending aortic aneurysm.
\end{abstract}

Results: Of the 123 patients with bicuspid aortic valve confirmed at surgery, by transthoracic echocardiography $76(62 \%)$ were identified preoperatively with bicuspid aortic valve, $12(10 \%)$ were misidentified with trileaflet aortic valve, and $35(28 \%)$ were nondiagnostic for valve morphology. In the same patients with bicuspid aortic valve, by cardiac magnetic resonance imaging $115(93 \%)$ were identified with bicuspid aortic valve, $5(4 \%)$ were misidentified with trileaflet aortic valve, and $3(2 \%)$ were nondiagnostic. The difference between transthoracic echocardiography and cardiac magnetic resonance imaging to determine the presence of bicuspid aortic valve was statistically significant $(P<.001)$. In the entire cohort of patients, transthoracic echocardiography was diagnostic for valve morphology in 155 patients $(71 \%)$ compared with cardiac magnetic resonance imaging, which was diagnostic in 212 patients $(97 \%)(P<.001)$.

Conclusions: Cardiac magnetic resonance imaging is more diagnostic than transthoracic echocardiography in determining the presence of bicuspid aortic valve. A significant factor is the rate of nondiagnostic transthoracic echocardiography for aortic valve morphology. Cardiac magnetic resonance imaging can be performed as a complementary test when transthoracic echocardiography is nondiagnostic for aortic valve morphology. ( $\mathrm{J}$ Thorac Cardiovasc Surg 2012;144:370-6)

Earn CME credits at

http://cme.ctsnetjournals.org

The prevalence of bicuspid aortic valve (BAV) in the population is $0.5 \%$ to $1.4 \% .^{1}$ Approximately $50 \%$ of patients requiring surgery for aortic stenosis (AS) have BAV. ${ }^{2}$ Moreover, patients with BAV have associated aortopathy of the ascending aorta, and up to $77 \%$ of patients aged more than 40 years with BAV have associated

From the Division of Cardiac Surgery, ${ }^{\mathrm{a}}$ Division of Cardiology, ${ }^{\mathrm{b}}$ and Department of Radiology, ${ }^{\mathrm{c}}$ Northwestern University, Feinberg School of Medicine, Bluhm Cardiovascular Institute at Northwestern Memorial Hospital, Chicago, Ill.

Disclosures: Authors have nothing to disclose with regard to commercial support.

Received for publication May 10, 2011; revisions received July 27, 2011; accepted for publication Sept 22, 2011; available ahead of print Dec 12, 2011.

Address for reprints: S. Chris Malaisrie, MD, 201 E Huron St, Galter Pavilion 11-140, Chicago, IL 60614 (E-mail: cmalaisr@nmh.org).

$0022-5223 / \$ 36.00$

Copyright (c) 2012 by The American Association for Thoracic Surgery doi:10.1016/j.jtcvs.2011.09.068 aneurysmal dilatation. ${ }^{3}$ Therefore, patients with BAV undergoing aortic valve surgery are typically evaluated for a coexisting ascending aortic aneurysm because a concomitant repair of the ascending aorta should be performed if the diameter of the aorta is greater than $4.5 \mathrm{~cm}^{4}$ Likewise, patients with known ascending aortic aneurysm should be evaluated for BAV. Because of the increased risk of aortic dissection in patients with BAV compared with patients with normal trileaflet aortic valve (TAV), a prophylactic repair of an isolated ascending aortic aneurysm is recommended sooner than in patients with TAV. ${ }^{5}$ Successful transcatheter aortic valve implantation using self- or balloon-expandable valve stents is dependent on the shape of the aortic annulus. Asymmetric aortic annuli as seen in patients with BAV are prone to stent misdeployment and valve distortion. ${ }^{6}$ Phase III trials studying transcatheter aortic valve implantation in highrisk patients with AS in the United States currently exclude patients with BAV.

The preoperative identification of BAV is important in the management of patients with aortic valve disease or 

Abbreviations and Acronyms
AI $=$ aortic insufficiency
AS $=$ aortic stenosis
$\mathrm{BAV}=$ bicuspid aortic valve
CMRI $=$ cardiac magnetic resonance imaging
iPAT $=$ integrated parallel acquisition technique
$\mathrm{TAV}=$ trileaflet aortic valve
TEE $=$ transesophageal echocardiography
TTE $=$ transthoracic echocardiography

ascending aortic aneurysm. We sought to determine the reliability of 2-dimensional, transthoracic echocardiography (TTE) in the preoperative identification of BAV by using surgical assessment of aortic valve morphology as the gold standard. In addition, we sought to determine the utility of cardiac magnetic resonance imaging (CMRI) as a complementary study to determine valve morphology.

\section{MATERIALS AND METHODS \\ Study Design}

A retrospective chart review of medical records was performed on 1203 patients who underwent an aortic valve operation at the Bluhm Cardiovascular Institute at Northwestern Memorial Hospital between April 2004 and December 2009. A total of 232 of these patients were identified as having undergone both preoperative TTE and CMRI. Fourteen patients had TTE or CMRI performed at other institutions and were not included in this study, leaving 218 patients for analysis. This study was approved by the institutional review board at Northwestern University (project STU00012288). The institutional review board waived the requirement of individual patient consent because the analysis was retrospective in nature.

\section{Baseline Characteristics}

The characteristics of this study group are summarized in Table 1. Of the 218 patients, $123(56 \%)$ had BAV and $95(44 \%)$ had TAV as determined at the time of surgery. Morphologic phenotypes of BAV included valves with 2 cusps and no raphe ("purely bicuspid") and valves with 2 cusps and 1 raphe ("fused commissure"). ${ }^{7}$ Patients with BAV were younger and had better ejection fraction, less coronary artery disease, less hypertension, less cerebrovascular disease, and less preoperative atrial fibrillation than patients with TAV (Table 1). Indications for operation in this study group included AS in 85 patients (39\%), aortic insufficiency (AI) in 56 patients $(26 \%)$, mixed AS/AI in 4 patients $(2 \%)$, and ascending aortic aneurysm in

TABLE 1. Characteristics of the 218 patients who underwent an aortic valve operation and had both preoperative transthoracic echocardiography and cardiac magnetic resonance imaging

\begin{tabular}{|c|c|c|c|c|}
\hline Characteristics N (\%) & $\begin{array}{c}\text { BAV } \\
n=123\end{array}$ & $\begin{array}{c}\text { TAV } \\
\mathbf{n}=\mathbf{9 5}\end{array}$ & $\begin{array}{c}\text { Total } \\
\mathbf{n}=\mathbf{2 1 8}\end{array}$ & $P$ value \\
\hline Age $(y)$, mean \pm SD & $53.02 \pm 13.30$ & $60.19 \pm 16.30$ & $56.15 \pm 15.07$ & $<.001$ \\
\hline Age range, $y$ & $23-82$ & $21-86$ & $21-86$ & \\
\hline Male gender & $98(79.7)$ & $68(71.6)$ & $166(76.1)$ & .164 \\
\hline NYHA class III/IV & $21(17.1)$ & $27(28.7)$ & $48(22.1)$ & .041 \\
\hline $\mathrm{EF}(\%)$ & $57.60 \pm 10.27$ & $53.61 \pm 13.12$ & $55.88 \pm 11.73$ & .017 \\
\hline \multicolumn{5}{|l|}{ Mean \pm SD } \\
\hline Angina & $13(10.6)$ & $16(16.8)$ & $29(13.3)$ & .176 \\
\hline Prior MI & $2(1.6)$ & $9(9.5)$ & $11(5.1)$ & .011 \\
\hline CAD & $24(20.5)$ & $37(39.4)$ & $61(28.9)$ & .003 \\
\hline 1 -vessel & $12(10.3)$ & $13(13.8)$ & 25 (11.9) & \\
\hline 2-vessel & $8(6.8)$ & $8(8.5)$ & $16(7.6)$ & \\
\hline 3 -vessel & $4(3.4)$ & $16(17.0)$ & $20(9.5)$ & \\
\hline Left main disease & $1(0.9)$ & $3(3.2)$ & $4(1.9)$ & .326 \\
\hline Previous PCI & $3(2.4)$ & $6(6.3)$ & $9(4.1)$ & .183 \\
\hline Hypertension & $59(48.0)$ & $62(65.3)$ & $121(55.5)$ & .011 \\
\hline Renal failure & $3(2.4)$ & $5(5.3)$ & $8(3.7)$ & .300 \\
\hline Hyperlipidemia & $59(48.0)$ & $49(51.6)$ & $108(49.5)$ & .597 \\
\hline Chronic lung disease & & & & .090 \\
\hline None & $120(97.6)$ & $86(90.5)$ & $206(94.5)$ & \\
\hline Mild & $2(1.6)$ & $5(5.3)$ & $7(3.2)$ & \\
\hline Moderate & $1(0.8)$ & $2(2.1)$ & $3(1.4)$ & \\
\hline Severe & $0(0.0)$ & $2(2.1)$ & $2(0.9)$ & \\
\hline Cerebrovascular disease & $5(4.1)$ & $10(10.5)$ & $15(6.9)$ & .062 \\
\hline CVA & $0(0.0)$ & $6(6.3)$ & $6(2.8)$ & .006 \\
\hline PVD & $1(0.8)$ & $7(7.4)$ & $8(3.7)$ & .023 \\
\hline Marfan syndrome & $0(0.0)$ & $6(6.3)$ & $6(2.8)$ & .006 \\
\hline History of atrial fibrillation & $6(4.9)$ & $14(14.7)$ & $20(9.2)$ & .012 \\
\hline
\end{tabular}

$S D$, Standard deviation; $N Y H A$, New York Heart Association; $P V D$, peripheral vascular disease; $E F$, ejection fraction; $M I$, myocardial infarction; $C A D$, coronary artery disease; $C V A$, cerebrovascular accident; $P C I$, percutaneous coronary intervention. 
TABLE 2. Operative indications for the 218 patients in the study group with delineation of secondary diagnosis when applicable

\begin{tabular}{lcccc}
\hline & BAV & TAV & Total & \\
& $\mathbf{n}=\mathbf{1 2 3}$ & $\mathbf{n = 9 5}$ & $\mathbf{n = 2 1 8}$ & $\boldsymbol{P}$ value \\
\hline AI & $28(23 \%)$ & $28(30 \%)$ & $56(26 \%)$ & .333 \\
Isolated AI & 9 & 19 & 28 & \\
AI+ aneurysm & 19 & 9 & 28 & \\
AS & $59(48 \%)$ & $26(27 \%)$ & $85(39 \%)$ & .003 \\
Isolated AS & 44 & 26 & 70 & \\
AS + aneurysm & 15 & 0 & 15 & \\
Aortic aneurysm & $32(26 \%)$ & $41(43 \%)$ & $73(33 \%)$ & .012 \\
Isolated aneurysm & 12 & 26 & 38 & \\
Aneurysm+AS & 5 & 0 & 5 & \\
Aneurysm+AI & 14 & 15 & 29 & \\
Aneurysm + AS/AI & 1 & 0 & 1 & \\
Mixed AS/AI & $4(3 \%)$ & $0(0 \%)$ & $4(2 \%)$ & .206 \\
\hline
\end{tabular}

$A I$, Aortic insufficiency; $A S$, aortic stenosis.

73 patients $(33 \%)$ (Table 2). Overall, 116 patients $(53 \%)$ had an aortic aneurysm whether they had BAV or TAV. More patients with BAV had AS ( \pm aneurysm) than did patients with TAV $(54 \%$ vs $27 \%, P<.001)$.

\section{Echocardiography Imaging Technique}

TTE images were obtained using one of several echocardiography systems: Sequoia 256 (Siemens Healthcare, Malvern, Pa), Philips Sonos 7500 or IE33 (Philips Medical Systems, Andover, Mass), or GE Vivid 7 (GE Healthcare, Waukesha, Wis). The aortic valve was examined in parasternal long- and short-axis images. In the parasternal long-axis view, coaptation off center and unequal leaflet lengths were suggestive of bicuspid valve anatomy. In the short-axis view, the aortic valve was diagnosed as bicuspid if only 2 cusps were seen during systole. When a raphe was seen during diastole, the diagnosis of bicuspid valve was made if only 2 sinuses were seen. Ejection fraction was calculated using the biplane method of disks (modified Simpson's rule). ${ }^{8}$

\section{Magnetic Resonance Imaging Technique}

CMRI studies were carried out on a 1.5T Avanto (Siemens Healthcare) with a 12-channel body array coil. The imaging protocol included multiplanar cine steady-state free precession, phase-contrast imaging, dynamic time-resolved contrast-enhanced magnetic resonance angiography, and delayed enhancement imaging.

Cine steady-state free precession was carried out in multiple short- and long-axis orientations, including specific right ventricular outflow tract, left ventricular outflow tract, and aortic valve orientations. The following imaging parameters were used: TR/TE 3.2/1.6 ms; flip angle 70 degrees; bandwidth $800 \mathrm{~Hz} /$ pixel; $256 \times 256$ matrix size; pixel size $2.2 \times 1.6$ $\mathrm{mm}^{2}$; 6-mm slice thickness; integrated parallel acquisition technique (iPAT) acceleration factor $\times 2$; acquisition time $5 \mathrm{~s} /$ slice; and temporal resolution $55 \mathrm{~ms} /$ frame.

Phase-contrast magnetic resonance imaging of the aortic valve was carried out using the following parameters: TR/TE $8 / 4 \mathrm{~ms}$; flip angle $30 \mathrm{de}-$ grees; bandwidth: $400 \mathrm{~Hz} /$ pixel; $256 \times 256$ matrix size; pixel size $2.2 \times 1.6$ $\mathrm{mm}^{2}$; 6-mm slice thickness; iPAT acceleration factor $\times 2$; acquisition time
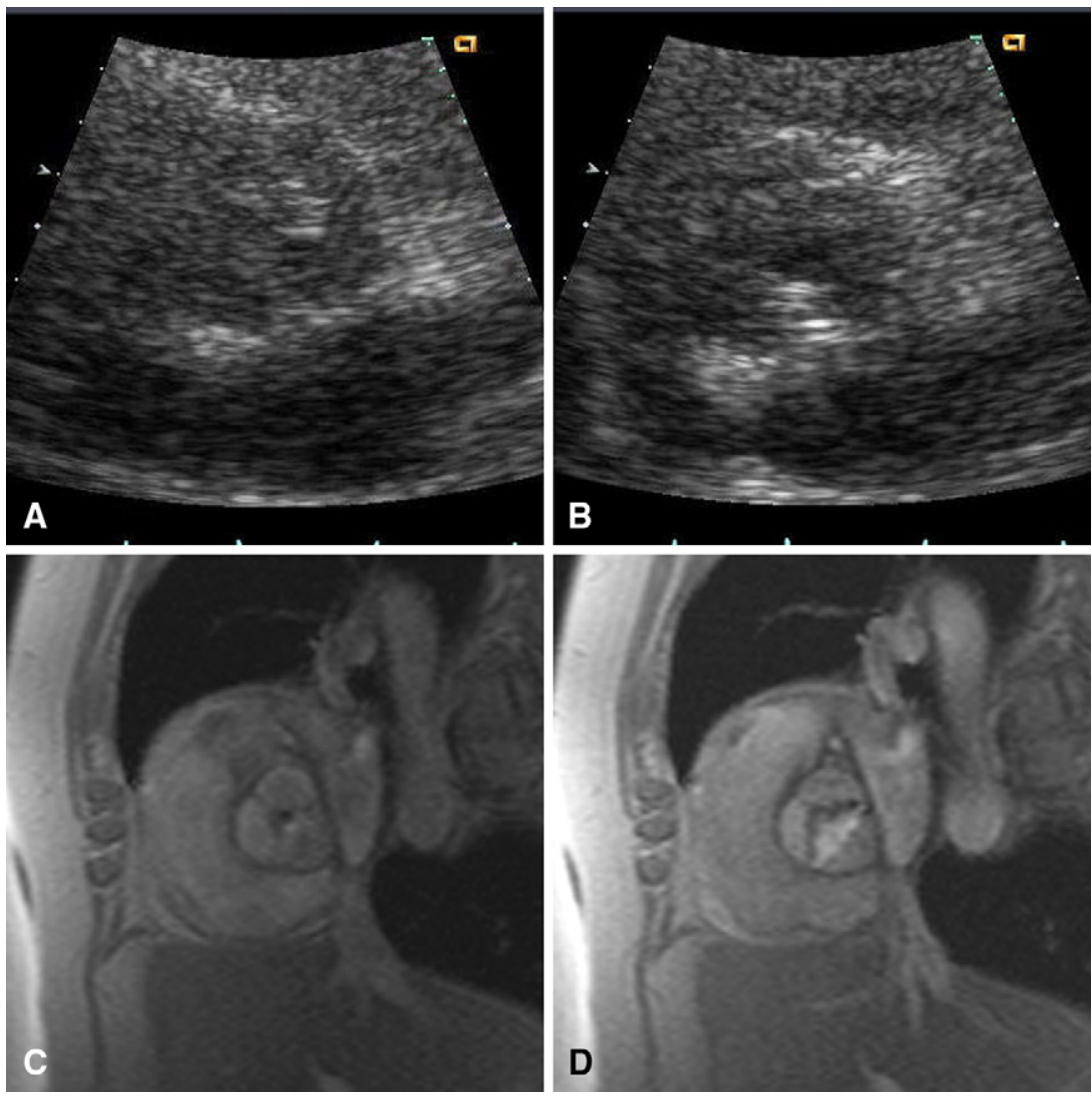

FIGURE 1. In patient A with bicuspid aortic valve, short-axis views by transthoracic echocardiography of (A) closed aortic valve and (B) open aortic valve were not well visualized and incorrectly identified trileaflet aortic valve. Axial views by cardiac magnetic resonance imaging of (C) closed aortic valve and (D) open aortic valve correctly identified bicuspid aortic valve. 

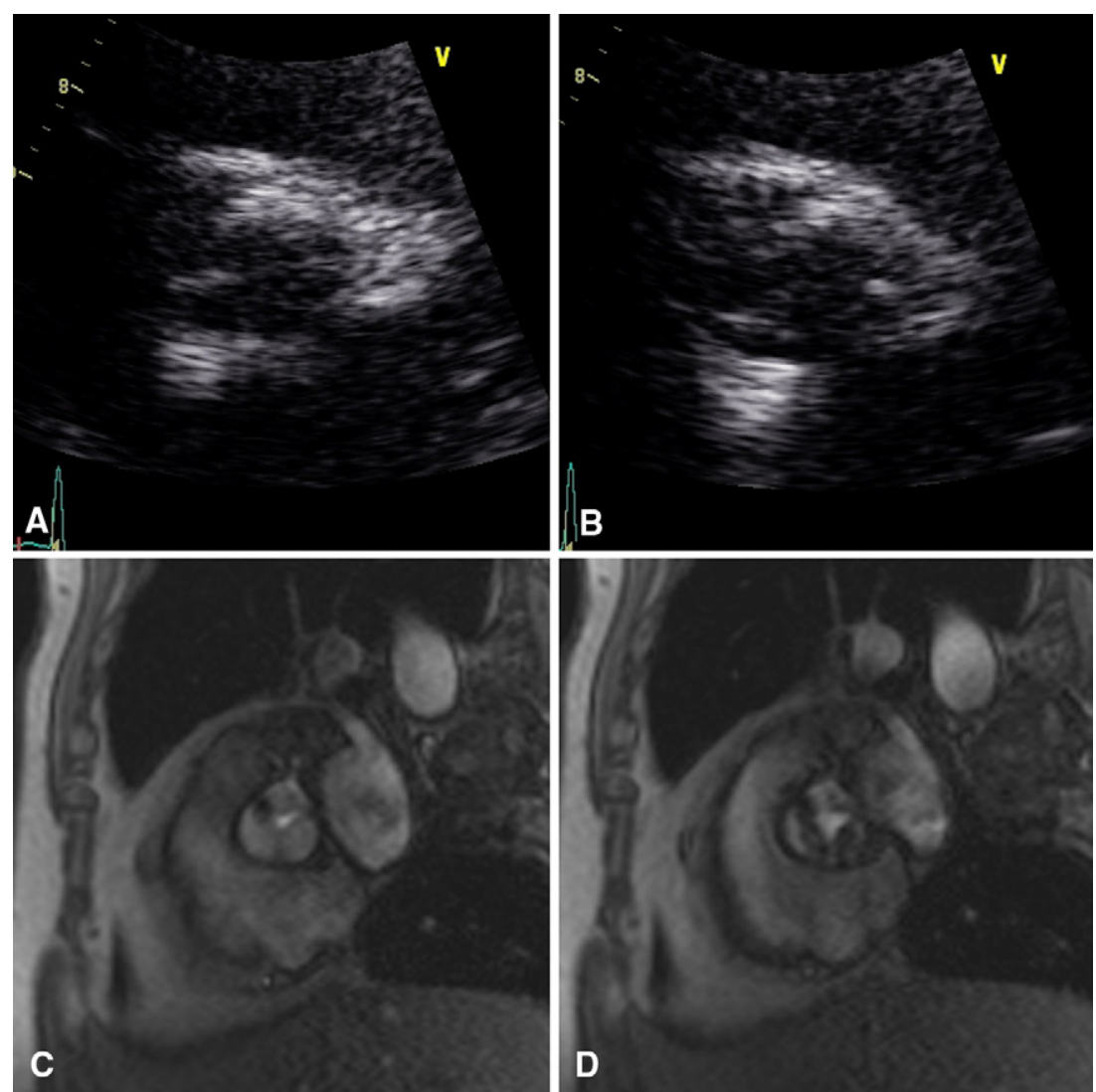

FIGURE 2. In patient B with bicuspid aortic valve, short-axis views by transthoracic echocardiography of (A) closed aortic valve and (B) open aortic valve correctly identified bicuspid aortic valve. Axial views by cardiac magnetic resonance imaging of (C) closed aortic valve and (D) open aortic valve incorrectly identified trileaflet aortic valve.

$10 \mathrm{~s} /$ slice; temporal resolution $65 \mathrm{~ms} /$ frame; and velocity encoding 80 to 300 $\mathrm{cm} / \mathrm{s}$. In-place, phase-contrast magnetic resonance imaging of the right and left ventricular outflow tracts were obtained with the velocity encoded in the plane of the slice along the estimated direction of flow. An appropriate velocity encoding was chosen on the basis of the aortic velocity, which is approximately 100 to $150 \mathrm{~cm} / \mathrm{s}$. Orthogonal transaxial slices of the aortic valve (3 slices per valve) were obtained from the in-plane images.

Time-resolved contrast-enhanced magnetic resonance angiography of the thoracic aorta was obtained in coronal and sagittal oblique orientations using a 3-dimensional gradient echocardiography fast low-angle shot pulse sequence with the following parameters: TR/TE $1.6 / 0.8 \mathrm{~ms}$; flip angle $30 \mathrm{de}-$ grees; bandwidth: $900 \mathrm{~Hz} /$ pixel; $256 \times 256$ matrix size; pixel size: $2.0 \times 1.5$ $\mathrm{mm}^{2}$; 1.5 to 3.0 -mm partition thickness; iPAT acceleration factor $\times 2$; acquisition time 1 to $3 \mathrm{~s} / 3 \mathrm{D}$ set. Echocardiography sharing (ie, TWIST, Siemens Healthcare) was used to further accelerate the acquisition, and 0.15 $\mathrm{mmol} / \mathrm{kg}$ of gadolinium-DTPA (Magnevist; Bayer Pharmaceuticas, Wayne, $\mathrm{NJ}$ ) was injected at $5 \mathrm{~mL} / \mathrm{s}$ via an intravenous cannula in the antecubital fossa in 2 divided doses.

Delayed enhanced imaging was obtained in short- and long-axis orientations using phase-sensitive inversion recovery TurboFLASH (Siemens; TR/TE 8/4 ms; flip angle 30 degrees; bandwidth: $400 \mathrm{~Hz} /$ pixel; $256 \times 256$ matrix size; pixel size: $2.2 \times 1.6 \mathrm{~mm}^{2}$; 6-mm slice thickness; iPAT acceleration factor $\times 2$; acquisition time $10 \mathrm{~s} /$ slice).

\section{Statistical Analysis}

Analysis was performed using standard binary classification, with BAV designated as the true positive value and TAV as the true negative value to measure sensitivity, specificity, positive predictive value, negative predictive value, and accuracy. Results classified as nondiagnostic were not applicable to the statistical binary measurement and thus were not used in the calculations.

Demographic variables and comorbidities were compared between patients who had BAV and patients who had TAV. Chi-square and Fisher exact tests were used for categoric variables, and $t$ tests were used for continuous variables. All statistical analyses were performed using SAS 9.2 statistical software (SAS Institute Inc, Cary, NC).

A subset of 10 TTE studies and $10 \mathrm{CMRI}$ studies were re-reviewed by an echocardiographer and CMRI specialist, respectively, to determine interobserver reliability with respect to valve morphology. Interobserver reliabilities were calculated using the kappa $(\kappa)$ statistic.

\section{RESULTS}

Of the 123 patients with BAV confirmed at surgery, by TTE 76 patients $(62 \%)$ were identified preoperatively with BAV, $12(10 \%)$ were misidentified with TAV, and 35 (28\%) were nondiagnostic for valve morphology. In the same patients with BAV, by CMRI $115(93 \%)$ were identified with BAV, $5(4 \%)$ were misidentified with TAV, and 3 $(2 \%)$ were nondiagnostic. Examples of concordant and discordant echocardiography and magnetic resonance imaging are shown in Figures 1 to 3. The difference between TTE (Table 3) and CMRI (Table 4) to determine the presence of BAV was statistically significant $(P<.001)$. 

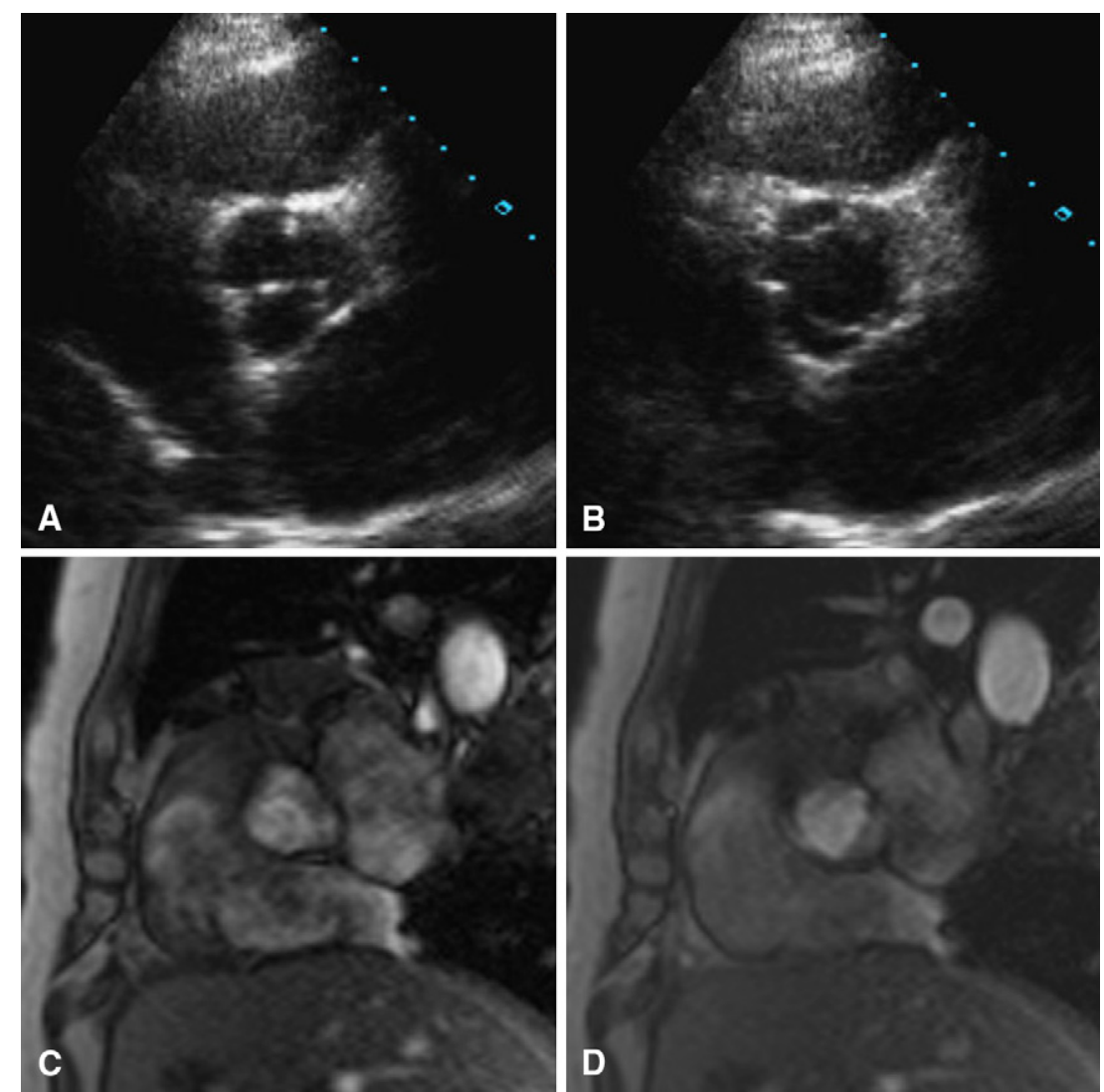

FIGURE 3. In patient $\mathrm{C}$ with bicuspid aortic valve, short-axis views by transthoracic echocardiography of (A) closed aortic valve and (B) open aortic valve and axial views by cardiac magnetic resonance imaging of (C) closed aortic valve and (D) open aortic valve both incorrectly identified trileaflet aortic valve.

In the entire cohort of patients, TTE was diagnostic for aortic valve morphology in 155 patients (71\%) compared with CMRI, which was diagnostic in 212 patients $(97 \%)$ $(P<.001)$. Patients were more likely $(P<.001)$ to have a diagnostic TTE if the primary indication for operation was not AS $(83 \%)$ than if the primary indication was AS (54\%) (Table 5). Likewise, CMRI was more diagnostic in patients without AS than in patients with AS (100\% vs $93 \%$, $P=.01$ ) (Table 6).

By including only diagnostic TTE and CMRI, the accuracy of TTE for preoperatively identifying patients with BAV was $90 \%(95 \% \mathrm{CI}, 85-95)$ and the accuracy of CMRI was $96 \%$ (95\% CI, 92-98) $(P>.05)$. The sensitivity, specificity, positive predictive value, and negative

TABLE 3. Classification of findings from transthoracic echocardiography results for the 218 patients in the study group

\begin{tabular}{lcc}
\hline $\begin{array}{c}\text { TTE } \\
\mathbf{n}=\mathbf{2 1 8}\end{array}$ & $\begin{array}{c}\text { BAV (surgery) } \\
\mathbf{n}=\mathbf{1 2 3}\end{array}$ & $\begin{array}{c}\text { TAV (surgery) } \\
\mathbf{n = 9 5}\end{array}$ \\
\hline BAV by TTE & 76 & 3 \\
TAV by TTE & 12 & 64 \\
Nondiagnostic & 35 & 28 \\
\hline
\end{tabular}

TTE, Transthoracic echocardiography; $B A V$, bicuspid aortic valve; $T A V$, trileaflet aortic valve. predictive value on the ability of TTE and CMRI to preoperatively identify BAV are summarized in Table 7.

Valve morphology was misidentified in 12 patients by TTE (Figure 1). Valve morphology was misidentified in 3 patients by CMRI (Figure 2). Two patients were misidentified by both TTE and CMRI (Figure 3). The likelihood that both TTE and CMRI incorrectly identified the aortic valve morphology was $1 \%(95 \% \mathrm{CI}, 0-2.2)$.

\section{DISCUSSION}

Previous studies on the accuracy of 2-dimensional echocardiography in the identification of BAV demonstrated a $93 \%$ accuracy but a $25 \%$ rate of nondiagnostic findings

TABLE 4. Classification of findings from cardiac magnetic resonance imaging results for the 218 patients in the study group

\begin{tabular}{ccc}
\hline CMRI & BAV (surgery) & TAV (surgery) \\
$\mathbf{n = 2 1 8}$ & $\mathbf{n = 1 2 3}$ & $\mathbf{n = 9 5}$ \\
\hline BAV by CMRI & 115 & 4 \\
TAV by CMRI & 5 & 88 \\
Nondiagnostic & 3 & 3 \\
\hline
\end{tabular}

$C M R I$, Cardiac magnetic resonance imaging; $B A V$, bicuspid aortic valve; $T A V$, trileaflet aortic valve. 
TABLE 5. Classification of diagnostic and nondiagnostic findings from transthoracic echocardiography according to primary operative indication for aortic valve operation as delineated in Table 2

\begin{tabular}{lcrrr}
\hline \multicolumn{1}{c}{$\begin{array}{c}\text { TTE } \\
\mathbf{n}=\mathbf{2 1 8}\end{array}$} & Aortic stenosis & \multicolumn{1}{c}{$\begin{array}{c}\text { Nonaortic } \\
\text { stenosis }\end{array}$} & \multicolumn{1}{c}{ Total } & $\boldsymbol{P}$ value \\
\hline Diagnostic & $48(54 \%)$ & $107(83 \%)$ & $155(71 \%)$ & $<.001$ \\
Nondiagnostic & $41(46 \%)$ & $22(17 \%)$ & $63(29 \%)$ & \\
\hline
\end{tabular}

TTE, Transthoracic echocardiography.

for aortic valve morphology. ${ }^{9}$ Failure to determine the morphology was attributed to valvular calcifications typical of patients with AS. ${ }^{10}$ Likewise, our study demonstrated an accuracy of $90 \%$ for TTE but a $29 \%$ rate of nondiagnostic findings, with the majority occurring in patients with AS. The typical findings of BAV on TTE have remained unchanged and include fusion of valve cusps, unequal valve cusp size, and elliptical opening (fishmouth) with 2 commissures during systole on the short-axis view. ${ }^{11}$ The long-axis view can show an asymmetric cusp closure line, systolic doming, and cusp prolapse. The current study confirms that TTE remains the initial study to evaluate the aortic valve.

One previous study has examined the accuracy of CMRI in identifying BAV. ${ }^{12}$ This study, using TTE as the gold standard, reported an accuracy of $97 \%$. Our results also showed a high accuracy of $96 \%$ using surgical assessment of the aortic valve as the gold standard. Moreover, CMRI was diagnostic for valve morphology in more than $97 \%$ of the cases. CMRI is able to obtain cine images, evenly spaced sequential short time frames, of the full cardiac cycle that allow greater visualization of cardiac function and morphology when viewed in a cinematic series. With the use of electrocardiogram gating, cardiac motion can be frozen frame by frame while minimizing artifacts. CMRI can be a useful complementary study when TTE is nondiagnostic for aortic valve morphology.

The inherent ability of CMRI to perform multiplanar imaging is also effective in assessing luminal and mural dimensions and changes in the aortic root and thoracic aorta distal to the aortic root. Moreover, the high degree of accuracy with which CMRI provides hemodynamic information about blood flow changes can be particularly critical in the diagnosis and evaluation of a coexisting ascending aortic aneurysm or aortic coarctation in patients with BAV. Our

TABLE 6. Classification of diagnostic and nondiagnostic findings from cardiac magnetic resonance imaging according to primary operative indication for aortic valve operation as delineated in Table 2

\begin{tabular}{lcccl}
\hline \multicolumn{1}{c}{$\begin{array}{c}\text { CMRI } \\
\mathbf{n}=\mathbf{2 1 8}\end{array}$} & Aortic stenosis & $\begin{array}{c}\text { Nonaortic } \\
\text { stenosis }\end{array}$ & Total & $\boldsymbol{P}$ value \\
\hline Diagnostic & $83(93 \%)$ & $129(100 \%)$ & $212(97 \%)$ & .010 \\
Nondiagnostic & $6(7 \%)$ & $0(0 \%)$ & $6(3 \%)$ & \\
\hline
\end{tabular}

CMRI, Cardiac magnetic resonance imaging.
TABLE 7. Ability of transthoracic echocardiography and cardiac magnetic resonance imaging to identify bicuspid aortic valve $(P>$ $.05)$ and accuracy in determining valve morphology by transthoracic echocardiography and cardiac magnetic resonance imaging $(P>\mathbf{0 5})$

\begin{tabular}{|c|c|c|c|c|c|}
\hline & Sensitivity & Specificity & $\begin{array}{c}\text { Positive } \\
\text { predictive } \\
\text { value }\end{array}$ & $\begin{array}{l}\text { Negative } \\
\text { predictive } \\
\text { value }\end{array}$ & Accuracy \\
\hline TTE & $86 \%$ & $96 \%$ & $96 \%$ & $84 \%$ & $90 \%$ \\
\hline CMRI & $96 \%$ & $96 \%$ & $97 \%$ & $95 \%$ & $96 \%$ \\
\hline
\end{tabular}

Analysis excludes nondiagnostic tests. TTE, Transthoracic echocardiography; CMRI, cardiac magnetic resonance imaging.

study showed that up to $53 \%$ of patients with $\mathrm{BAV}$ requiring surgery had an ascending aortic aneurysm. Accurate measurement of aortic diameter is important in surgical indications for aneurysm replacement. Current guidelines state that the ascending aorta should be replaced when the diameter is $4.5 \mathrm{~cm}$ or greater and aortic valve surgery is also required. ${ }^{13}$

Other modalities to identify aortic valve morphology include transesophageal echocardiography (TEE), real-time 3-dimensional echocardiography, and multidetector computed tomography. Although both TEE and 3-dimensional echocardiography can provide more detailed imaging, application to aortic valve morphology is limited. TEE is an invasive study, and 3-dimensional echocardiography has only been shown to be useful in estimating the severity of AS. ${ }^{14-16}$ Multidetector computed tomography, similar to CMRI, has excellent spatial and temporal resolution in aortic valve imaging and thus may be useful in assessing the degree of valve calcification. However, patient exposure to radiation is a consideration. Multidetector computed tomography is gated only to diastole and cannot provide information for the full cardiac cycle without exposing patients to a prohibitively high-risk amount of radiation, and it provides no information on hemodynamics.

\section{Study Limitations}

Limitations of this study include its retrospective nature. Although all TTE and CMRI studies were performed and interpreted at a single center, the reading physician and technician were not standardized. Because the study included echocardiograms acquired more than 7 years ago using systems of varying ages, image quality in some studies may have been affected by older technology. In addition, because it is our protocol to obtain CMRI in patients with BAV to evaluate the thoracic aorta, a bias toward more nondiagnostic TTE studies was likely introduced in this study group. The presence of severe calcification common to this study group with end-stage aortic valve disease may have influenced a nondiagnostic diagnosis by TTE and thus its data on sensitivity. In cases when CMRI was only performed after inconclusive results from TTE, 
pre-selection bias in favor of the former may be possible; however, to minimize any further bias, consistency in the analysis of subject records and standardization in reporting data was maintained throughout the study.

\section{CONCLUSIONS}

Two-dimensional TTE is the initial test obtained in patients with aortic valve disease. However, aortic valve morphology cannot be determined in a significant number of patients, particularly patients with AS. CMRI is a useful investigation for those patients whose aortic valve morphology cannot be determined by TTE. In addition, CMRI is useful in imaging the thoracic aorta in patients with BAV who may have an associated ascending aortic aneurysm. Accurate preoperative identification of BAV has implications in surgical indications for patients with isolated ascending aortic aneurysms, surgical management of coexisting ascending aortic aneurysm during aortic valve surgery, and patient selection for transcatheter aortic valve implantation.

\section{References}

1. Basso C, Boschello M, Perrone C, Mecenero A, Cera A, Bicego D, et al. An echocardiographic survey of primary school children for bicuspid aortic valve. Am J Cardiol. 2004;93:661-3.

2. Ward C. Clinical significance of the bicuspid aortic valve. Heart. 2000;83:81-5.

3. Cecconi M, Manfrin M, Moraca A, Zanoli R, Colonna PL, Bettuzzi MG, et al. Aortic dimensions in patients with bicuspid aortic valve without significant valve dysfunction. Am J Cardiol. 2005;95:292-4.

4. Borger MA, Preston M, Ivanov J, Fedak PW, Davierwala P, Armstrong S, et al. Should the ascending aorta be replaced more frequently in patients with bicuspid aortic valve disease? J Thorac Cardiovasc Surg. 2004;128:677-83.

5. Bonow RO, Carabello BA, Chatterjee K, de Leon AC Jr, Faxon DP, Freed MD, et al. 2008 Focused update incorporated into the ACC/AHA 2006 guidelines for the management of patients with valvular heart disease: a report of the American College of Cardiology/American Heart Association Task Force on Practice Guidelines (Writing Committee to Revise the 1998 Guidelines for the Management of Patients With Valvular Heart Disease): endorsed by the Society of Cardiovascular Anesthesiologists, Society for Cardiovascular Angiography and
Interventions, and Society of Thoracic Surgeons. Circulation. 2008;118: e523-661.

6. Zegdi R, Ciobotaru V, Noghin M, Sleilaty G, Lafont A, Latremouille C, et al. Is it reasonable to treat all calcified stenotic aortic valves with a valved stent? Results from a human anatomic study in adults. J Am Coll Cardiol. 2008;51:579-84.

7. Sievers HH, Schmidtke C. A classification system for the bicuspid aortic valve from 304 surgical specimens. J Thorac Cardiovasc Surg. 2007;133:1226-33.

8. Lang RM, Bierig M, Devereux RB, Flachskampf FA, Foster E, Pellikka PA, et al. Recommendations for chamber quantification: a report from the American Society of Echocardiography's Guidelines and Standards Committee and the Chamber Quantification Writing Group, developed in conjunction with the European Association of Echocardiography, a branch of the European Society of Cardiology. J Am Soc Echocardiogr. 2005;18:1440-63.

9. Brandenburg RO Jr, Tajik AJ, Edwards WD, Reeder GS, Shub C, Seward JB. Accuracy of 2-dimensional echocardiographic diagnosis of congenitally bicuspid aortic valve: echocardiographic-anatomic correlation in 115 patients. Am J Cardiol. 1983;51:1469-73.

10. Joziasse IC, Vink A, Cramer MJ, van Oosterhout MF, van Herwerden LA, Heijmen R, et al. Bicuspid stenotic aortic valves: clinical characteristics and morphological assessment using MRI and echocardiography. Neth Heart J. 2011;19: 119-25.

11. Baumgartner H, Hung J, Bermejo J, Chambers JB, Evangelista A, Griffin BP, et al. Echocardiographic assessment of valve stenosis: EAE/ASE recommendations for clinical practice. Eur J Echocardiogr. 2009;10:1-25.

12. Gleeson TG, Mwangi I, Horgan SJ, Cradock A, Fitzpatrick P, Murray JG. Steadystate free-precession (SSFP) cine MRI in distinguishing normal and bicuspid aortic valves. J Magn Reson Imaging. 2008;28:873-8.

13. Hiratzka LF, Bakris GL, Beckman JA, Bersin RM, Carr VF, Casey DE Jr, et al. 2010 ACCF/AHA/AATS/ACR/ASA/SCA/SCAI/SIR/STS/SVM guidelines for the diagnosis and management of patients with Thoracic Aortic Disease: a report of the American College of Cardiology Foundation/American Heart Association Task Force on Practice Guidelines, American Association for Thoracic Surgery, American College of Radiology, American Stroke Association, Society of Cardiovascular Anesthesiologists, Society for Cardiovascular Angiography and Interventions, Society of Interventional Radiology, Society of Thoracic Surgeons, and Society for Vascular Medicine. Circulation. 2010;121:e266-369.

14. Blot-Souletie N, Hebrard A, Acar P, Carrie D, Puel J. Comparison of accuracy of aortic valve area assessment in aortic stenosis by real time three-dimensional echocardiography in biplane mode versus two-dimensional transthoracic and transesophageal echocardiography. Echocardiography. 2007;24:1065-72.

15. Goland S, Trento A, Iida K, Czer LS, De Robertis M, Naqvi TZ, et al. Assessment of aortic stenosis by three-dimensional echocardiography: an accurate and novel approach. Heart. 2007;93:801-7.

16. Gutierrez-Chico JL, Zamorano JL, Prieto-Moriche E, Hernandez-Antolin RA, Bravo-Amaro M, Perez de Isla L, et al. Real-time three-dimensional echocardiography in aortic stenosis: a novel, simple, and reliable method to improve accuracy in area calculation. Eur Heart J. 2008;29:1296-306. 